\title{
Downregulation of miR-27b promotes skin wound healing in a rat model of scald burn by promoting fibroblast proliferation
}

\author{
QINGXIA BI* , JINGYAN LIU* ${ }^{*}$ XUEMING WANG and FURONG SUN \\ Department of Burn and Cosmetology, The Affiliated Yantai Yuhuangding Hospital \\ of Qingdao University, Yantai, Shandong 264000, P.R. China
}

Received September 9, 2019; Accepted April 29, 2020

DOI: $10.3892 /$ etm.2020.9191

\begin{abstract}
The aim of the present study was to investigate the effect and mechanism of action of microRNA (miR)-27b on skin wound healing in rats with deep second-degree scald burns and in BJ human skin fibroblast cells. Rat models with deep second-degree scald burns were constructed and injected with miR-27b mimics and inhibitors at the wound site daily for 21 days. Healing of burned skin tissues was observed at $0,3,7,14$ and 21 days following modeling. H\&E and Masson staining were used to observe the pathological structure and degree of collagen fibers in the burned skin tissues. The effects of miR-27b on BJ cell proliferation and migration were determined by MTT and scratch assays. Matrix metalloproteinase-1 (MMP-1), $\alpha$-smooth muscle actin ( $\alpha$-SMA), collagen I and collagen III expression in rat skin tissues and BJ cells were measured via reverse transcription-quantitative PCR and western blot analysis. The results of the in vivo experiments demonstrated that miR-27b inhibition accelerated scalded skin healing and induced fibroblast growth. Furthermore, the in vitro experiments revealed that miR-27b inhibition increased BJ cell proliferation and migration. Furthermore, miR-27b inhibition upregulated MMP-1, $\alpha$-SMA, collagen I and collagen III expression in the skin tissues and cells, while the overexpression of miR-27b demonstrated the opposite effect. In conclusion, the results of the present study revealed that miR-27b inhibition increased fibroblast proliferation, thereby accelerating scald wound healing in rats.
\end{abstract}

Correspondence to: Dr Furong Sun, Department of Burn and Cosmetology, The Affiliated Yantai Yuhuangding Hospital of Qingdao University, 20 Yuhuangding East Road, Yantai, Shandong 264000, P.R. China

E-mail: rjcffcso@163.com

*Contributed equally

Key words: microRNA-27b, deep second-degree scald burn, fibroblasts, wound healing

\section{Introduction}

Scald burns are common accidental injuries usually caused by exposure to hot liquids or metals (1). The degree of skin damage caused by scald burns is primarily associated with the temperature and duration of exposure and depth is determined by pathological examination $(2,3)$. The determination of depth is consistent with the clinical 'three degree quartering' method (4). Furthermore, second-degree scald burns may be divided into shallow and deep burns (4). Deep second-degree scald burns are characterized by a deep dermal layer burn and the healing process is comprised of various biological processes involving numerous cell and tissue components, including inflammatory response, cell proliferation and migration and wound remodeling, as three overlapping processes $(5,6)$.

At present, antibiotics and silver salt are the major components of chemical drugs used to treat scald burns (7). However, chemical drugs have a single mechanism of action and have low efficacy (7). Recently, antibiotic abuse and bacterial drug resistance have increased, leading to complications with the use of chemical drugs in the treatment of burns and scald $(8,9)$. Due to this, gene targeting therapy for scald burns may be a focus of interest.

MicroRNAs (miRNAs or miRs) are endogenous, eukaryotic non-coding RNAs with various regulatory functions (10). By regulating the expression of target genes, miRNAs participate in important physiological processes, including growth, development, differentiation and metabolism, and serve an important biological function (11). Abnormal miRNA expression has been frequently reported in malignant tumors in humans, including in lung cancer and prostate cancer, in which they serve roles in proliferation, apoptosis and invasion (12-14). Furthermore, recent studies have demonstrated that multiple miRNAs are involved in scald burn wound healing $(15,16)$.

miR-27b is abnormally expressed in liver cancer and kidney cancer, and has been reported to be associated with angiogenesis $(17,18)$. However, the role of miR-27b in the wound healing process of scald burns has not been previously reported in the literature. Therefore, the present study evaluated the effect of miR-27b on skin healing by constructing a rat model of deep second-degree scald burns. In addition, the effect of miR-27b on the proliferation and migration of BJ human skin fibroblast 
cells was investigated using an in vitro model. In short, the present study investigated the role and mechanism of action of miR-27b in the healing of scald burns in rats and in BJ fibroblast cells, providing a novel strategy for the treatment of scald burns.

\section{Materials and methods}

Animals. A total of 72 male Sprague Dawley rats (weight, 230-250 g; age, 8-9 weeks) were purchased from the Jinan Pengyue Experimental Breeding Co., Ltd. with license no. SCXK (lu) 2014-0007. All rats were housed at temperatures of $22-25^{\circ} \mathrm{C}$ with a humidity of $50-60 \%$ and $12 \mathrm{~h}$ light/dark cycles. Rats had free access to drinking water and food for 1 week. The current study was approved by the Committee on Animal Protection and Use of the Affiliated Yantai Yuhuangding Hospital of Qingdao University (Yantai, China) and was conducted in strict accordance with the National Institute of Health guidelines (pub. no. 85-23; revised 1996).

Establishment of the deep second-degree scald burn rat model. The control group did not receive a scald burn. The other 5 groups of rats were used to establish a deep second-degree scald burn model. The rats were administered deep anesthesia via intraperitoneal injection of $40 \mathrm{mg} / \mathrm{kg} 3 \%$ pentobarbital sodium following fasting for $12 \mathrm{~h}$. Hair was removed from the back (area, $3 \times 3 \mathrm{~cm}$ ) using $8 \%$ sodium sulfide (Zhejiang Shiyan Medicine Co., Ltd.) and $10 \mathrm{ml}$ water at $80^{\circ} \mathrm{C}$ was applied for 10 sec to induce a scald wound (area, $2.5 \times 2.5 \mathrm{~cm}$ ) and establish the model. Rats were then intraperitoneally injected with $30 \mathrm{ml} / \mathrm{kg}$ of Ringer's solution (Zhejiang Shiyan Medicine Co., Ltd.) and the scald site was treated with a sterile gauze (19).

Following modeling, rats in each group were subcutaneously injected (depth, 2.5-3 mm) with corresponding therapeutic agents around of the trauma site every day for 21 days and controls were injected with equal amounts of normal saline. miR-27b mimic control reagent (cat. no. mirln0000001-1-5), miR-27b mimics (cat. no. MIMAT0000419), miR-27b inhibitor control reagent (cat. no. mir2n00000000419-1-5) and miR-27b inhibitor reagent (cat. no. mir20000419-1-5) were all obtained from Guangzhou Ruibo Biological Co., Ltd. The mimics, inhibitors and control reagents $(100 \mu \mathrm{g})$ were

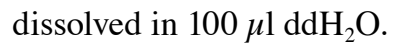

No animals were lost during the experiment. A total of 72 rats were randomly divided into 6 groups $(n=12)$. The controls were injected with equal amounts of saline. Following the establishment of the deep second-degree scald burn model, the remaining 5 groups were treated as follows: The model group, which was injected subcutaneously with equal volumes of saline; the miR-27b mimics (miR27b) group, which was injected subcutaneously with $4 \mu \mathrm{g} / \mathrm{kg}$ of miR-27b mimics; the miR-27b mimics control (MC) group, which was injected subcutaneously with $4 \mu \mathrm{g} / \mathrm{kg}$ miR-27b mimics control reagent; miR-27b inhibitor (inhibitor) group, which was injected subcutaneously with $4 \mu \mathrm{g} / \mathrm{kg}$ of miR-27b inhibitor; and the miR-27b inhibitor control (IC) group, which was injected with $4 \mu \mathrm{g} / \mathrm{kg}$ miR-27b inhibitor control reagent.

Measurement of wound healing rate. The rats were intraperitoneally anesthetized with $40 \mathrm{mg} / \mathrm{kg} 1 \%$ pentobarbital sodium
(Zhejiang Shiyan Medicine Co., Ltd.) on days 0, 3, 7, 14 and 21 following modeling and images of the scald wounds were captured. The wound was covered with sterile plastic film and the unhealed area of the wound was traced in order to measure the area of unhealed skin and the wound healing rate was calculated at each time-point as follows: Wound healing rate $=[$ (original wound area - unhealed wound area $) /$ original wound area] $\times 100 \%$.

The rats were anesthetized via intraperitoneal injection of $40 \mathrm{mg} / \mathrm{kg} 1 \%$ pentobarbital sodium (Zhejiang Shiyan Medicine Co., Ltd.) $2 \mathrm{~h}$ after the end of treatment on day 21 days post-modelling. Following anesthesia, the rats were sacrificed by cervical dislocation. Wound tissue or regenerated tissue $(\sim 1 \times 1 \mathrm{~cm})$ from the middle or the side of the wound was excised and were either fixed in $4 \%$ paraformaldehyde (Beijing Solarbio Science \& Technology Co., Ltd.) for H\&E and Masson staining or cultured in liquid nitrogen (Beijing Solarbio Science \& Technology Co., Ltd.) and transferred to the refrigerator at $-80^{\circ} \mathrm{C}$ for reverse transcription-quantitative PCR (RT-qPCR) and western blot analysis.

$H \& E$ staining. Tissues from the healing scald wounds of the rats were excised and fixed with $4 \%$ paraformaldehyde at $37^{\circ} \mathrm{C}$ for $48 \mathrm{~h}$ (Beijing Solarbio Science \& Technology Co., Ltd.). Fixed tissues were dehydrated, cleared and embedded in paraffin. The tissues were cut into $5-\mu \mathrm{m}$ sections and then dried, dewaxed and dehydrated with graded series of ethanol (Zhejiang Shiyan Medicine Co., Ltd.; 100\% ethanol for $5 \mathrm{~min}$, $95 \%$ ethanol for $5 \mathrm{~min}, 90 \%$ ethanol for $5 \mathrm{~min}, 80 \%$ ethanol for $5 \mathrm{~min}$ and $70 \%$ ethanol for $5 \mathrm{~min}$ ). Hematoxylin was used for staining for $5 \mathrm{~min}$ at room temperature and then eosin for $2 \mathrm{~min}$ at room temperature. Skin tissue morphology was observed at a magnification of x400 with an optical microscope (Olympus BX51; Olympus Corp.).

Masson staining. Skin tissue sections were stained with lignin (AR1069; Wuhan Boster Biological Technology, Ltd.) for $5 \mathrm{~min}$ at $25^{\circ} \mathrm{C}$ and treated with acidic ethanol differentiation solution (Wuhan Boster Biological Technology,Ltd.).Following staining with Masson bluing solution, lichun red magenta dyeing solution (G1340; Beijing Solarbio Science \& Technology Co., Ltd.) was used for staining at $25^{\circ} \mathrm{C}$ for $10 \mathrm{~min}$. Following leaching with $2 \%$ glacial acetic acid solution (Wuhan Boster Biological Technology, Ltd.) at $25^{\circ} \mathrm{C}$ for $2 \mathrm{~min}$, the sections were washed with phosphomolybdate solution (Wuhan Boster Biological Technology, Ltd.) for $3 \mathrm{~min}$ and then stained with aniline blue staining solution for $5 \mathrm{~min}$ at $25^{\circ} \mathrm{C}$. The slices were dehydrated with $95 \%$ ethanol and anhydrous ethanol, and permeabilized with xylene and sealed with neutral gum. Collagen fibrosis in skin tissues was observed at a magnification of $\mathrm{x} 400$ using an optical microscope (Olympus BX51; Olympus Corp.).

BJ cell culture and grouping. BJ cells (CRL-2522; American Type Culture Collection) were cultured in Dulbecco's modified Eagle's medium (Gibco; Thermo Fisher Scientific, Inc.) and supplemented with $1 \%$ penicillin-streptomycin (Beijing Solarbio Science \& Technology Co., Ltd.) and $10 \%$ fetal bovine serum (Sigma-Aldrich; Merck KGaA). Cells were incubated in a cell incubator (Thermo Fisher Scientific, Inc.) at $37^{\circ} \mathrm{C}$ with $5 \% \mathrm{CO}_{2}$ and saturated humidity. 
BJ cells in the logarithmic phase were seeded into 6-well plates $\left(2 \times 10^{5} /\right.$ well) and inoculated for $24 \mathrm{~h}$. The wells were divided into the control, miR-27b, MC, inhibitor and IC groups and Lipofectamine ${ }^{\mathrm{TM}} 2000$ transfection reagent (Invitrogen; Thermo Fisher Scientific, Inc.) was used to transfect corresponding reagents into cells for $12 \mathrm{~h}$ to construct BJ cells exhibiting miR-27b overexpression or inhibition.

MTT assay. BJ cell proliferation was determined via MTT assay. A cell suspension of total of $1 \times 10^{4} / \mathrm{ml}$ was inoculated into 96-well plates $(100 \mu \mathrm{l} /$ well $)$ and cultured in $5 \% \mathrm{CO}_{2}$ and saturated humidity at $37^{\circ} \mathrm{C}$ for $24,48,72$ and $96 \mathrm{~h}$. Subsequently, $20 \mu \mathrm{l}$ MTT solution $(5 \mathrm{mg} / \mathrm{ml})$ was added to each well, followed by incubation at $37^{\circ} \mathrm{C}$ for $4 \mathrm{~h}$. The supernatant was removed and $200 \mu \mathrm{l}$ DMSO (Sigma-Aldrich; Merck KGaA) was added to each well. The cells were blown evenly and the optical density was measured at $490 \mathrm{~nm}$ using the 190 SpectraMax spectrophotometer (Eppendorf).

Wound-healing assay. BJ cell migration was evaluated with a wound-healing assay. Cells from each group were suspended at a concentration of $3 \times 10^{5} / \mathrm{ml}$ and were inoculated into 6-well plates and the cell layer was cultured to cover the 6-well plate. Cells were scratched with a $10-\mu 1$ pipette tip and cell debris was removed. An inverted microscope (Olympus Corp.) was used to capture images and at time-points 0 and $24 \mathrm{~h}$ following scratching and wound healing rate was calculated using ImageJ software (version 1.46r; National Institutes of Health,).

RT- $q P C R$ analysis. Total RNA from skin tissue and BJ cells was extracted using a Total RNA Extraction kit (Invitrogen; Thermo Fisher Scientific, Inc.) and RNA was reverse-transcribed into cDNA using SuperScript III Reverse Transcriptase (Thermo Fisher Scientific, Inc.), according to the manufacturer's protocol. SYBR Green PCR kit (Qiagen) was used as the fluorophorem according to the manufacturer's protocol. RT-qPCR was performed using $2 \mu \mathrm{l} \mathrm{cDNA}$ as a template. The thermocycling conditions were $95^{\circ} \mathrm{C}$ for $10 \mathrm{~min}, 95^{\circ} \mathrm{C}$ for $15 \mathrm{sec}$ and $60^{\circ}$ for $30 \mathrm{sec}$ for a total of 40 cycles. $\beta$-actin was used as the reference gene and relative expression levels were calculated according to the $2^{-\Delta \Delta \mathrm{Cq}}$ method (20). The sequences of all primers (Shanghai Shenggong Biology Engineering Technology \& Services Co., Ltd.) were as follows: Collagen I forward, 5'-CCAGTCACCTGCGTACAGAACG-3' and reverse, 5'-GCCAGTGTCTCCTTTGGGTCC-3'; collagen III forward, 5'-AGGCAACAGTGGTTCTCCTG-3' and reverse, 5'-GAC CTCGTGCTCCAGTTAGC-3', matrix metalloproteinase-1 (MMP-1)forward,5'-CCGAGATCTCATGCACAGCTTTCCT CCACT-3' and reverse, 5'-CGGTTAACCGTCAATTTTTCC TGCAGTTG-3', $\alpha$-smooth muscle actin ( $\alpha$-SMA) forward, 5'-CCACCGCAAATGCTTCTAAGT-3' and reverse, 5'-GGC AGGAATGATTTGGAAAGG-3'; and $\beta$-actin forward, 5'-GATCATTGCTCCTCCTGAGC-3' and reverse, 5'-CACCT TCACCGTTCCAGTTT-3'.

Western blot analysis. Total protein from skin tissue and BJ cells was extracted using RIPA buffer (Beyotime Institute of Biotechnology) and then quantified using a Pierce ${ }^{\mathrm{TM}}$ BCA Protein assay kit (cat. no. 23225; Thermo Fisher Scientific, Inc.). A total of $40 \mu \mathrm{g}$ protein/lane was separated via SDS-PAGE
(Mini-Protean-3; Bio-Rad Laboratories, Inc.) and transferred to polyvinylidene difluoride membranes (EMD Millipore). The membrane was blocked with $5 \%$ skimmed milk powder solution for $1 \mathrm{~h}$ and then incubated with the following primary antibodies at $4{ }^{\circ} \mathrm{C}$ overnight: Rabbit anti-collagen I antibody (cat. no. ab34710; 1:2,000 dilution; Abcam), rabbit anti-collagen III antibody (cat. no. ab7778; 1:5,000 dilution; Abcam), rabbit anti-MMP-1 antibody (cat. no. ab137332; 1:1,000 dilution; Abcam), rabbit anti- $\alpha$-SMA antibody (cat. no. YM-H0645; 1:500 dilution; Shanghai Yuan $\mathrm{Mu}$ Biotechnology Co., Ltd.) and rabbit anti- $\beta$-actin antibody (cat. no. ab8227; 1:2,00 dilution; Abcam). The protein bands were then incubated with secondary antibody goat anti-rabbit IgG (cat. no. ab6721; 1:2,000 dilution; Abcam) at room temperature for $2 \mathrm{~h}$ and treated with enhanced chemiluminescence solution (Thermo Fisher Scientific, Inc.). $\beta$-actin was used as the internal reference and the gray values of protein bands were quantitatively analyzed by ImageJ software (version 1.46r; National Institutes of Health).

Statistical analysis. All data were expressed as the mean \pm standard deviation and SPSS software (version 19.0; IBM Corp.) was used to analyze data. One-way analysis of variance and Tukey's post hoc test was used. All experiments were performed in triplicate. $\mathrm{P}<0.05$ was considered to indicate a statistically significant difference.

\section{Results}

Determination of skin healing rate in rats. A rat model of deep second-degree scald burn was established and the wound healing rate of each group was determined (Fig. 1A and B). The degree of scald healing in each group demonstrated different degrees of recovery in a time-dependent manner following modelling. There was no significant difference in recovery between the MC, IC and model groups. However, at days 7, 14 and 21 following modelling, the healing rate was significantly higher in the miR-27b inhibitor group and significantly lower in the miR-27b group compared with the model group, respectively $(\mathrm{P}<0.05)$. These results indicated that miR-27b inhibition significantly accelerated the degree of scald burn healing in rats, while overexpression of miR-27b had the opposite effect.

Observation of tissue morphology and collagen fibrosis in rats. HE staining was used to observe tissue morphology of scald burn skin in rats in each group 21 days post-operation (Fig. 2A). The skin tissue cells of controls were organized and exhibited non-inflammatory cell infiltration. The model, MC and IC groups exhibited disordered cells and a certain degree of epidermal epithelialization. Furthermore, cells in the inhibitor group were in an ordered arrangement, were observed to increase in number and exhibited re-epithelialization compared with the model group. The miR-27b group demonstrated increased inflammatory cell infiltration and was observed to exhibited a higher degree of pathological damage compared with the model group.

Masson staining was used to observe the degree of collagen fibrosis in the skin tissues of rats in each group (Fig. 2B). The collagenous fibers in the control group were organized, while 


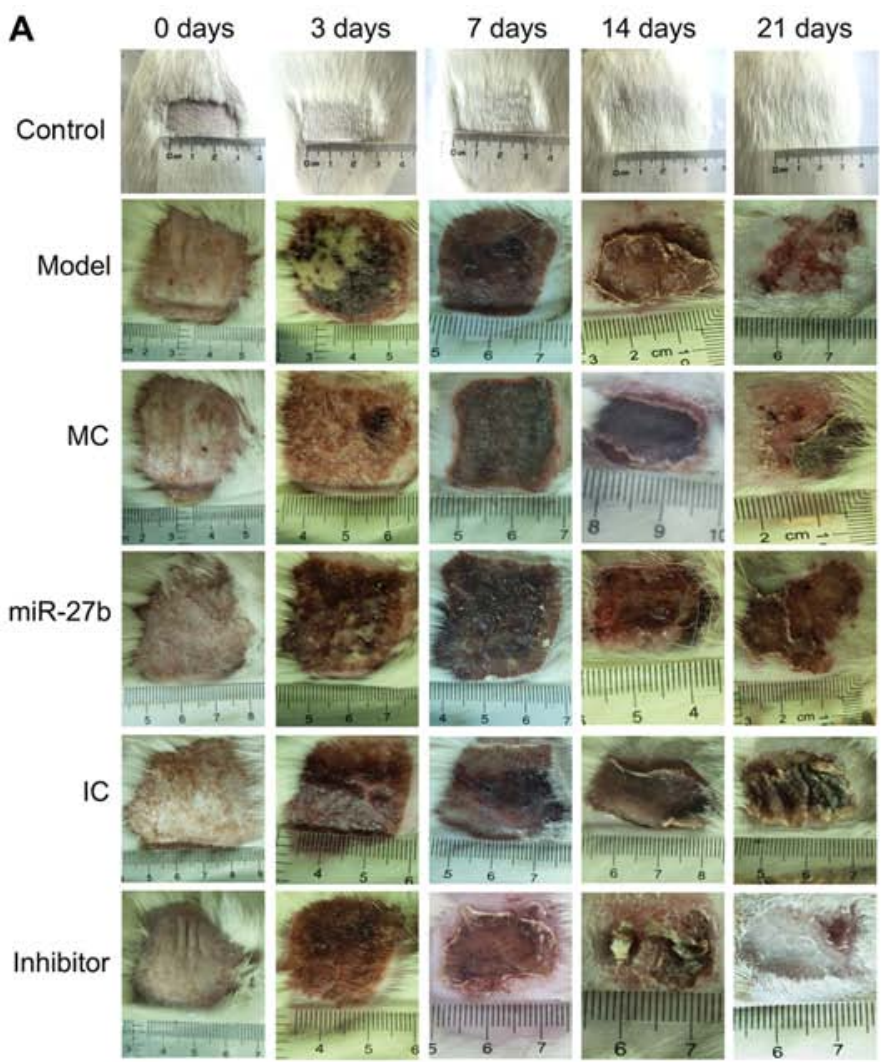

B

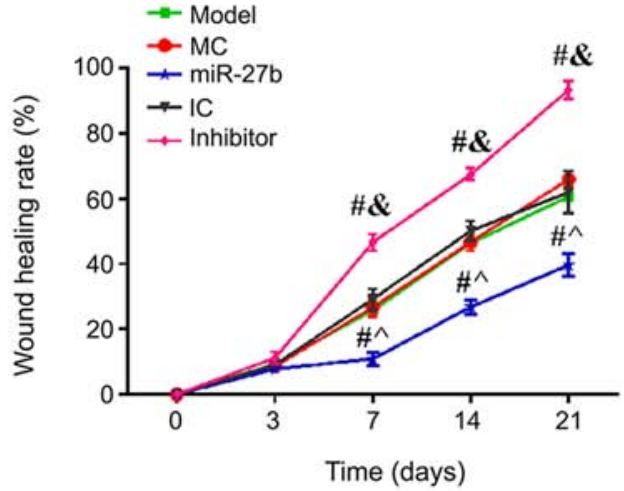

Figure 1. Determination of the skin healing rate in rats. (A) Images of scald burn surfaces for each group of rats. (B) Quantification of wound healing rate in each group of rats. ${ }^{\#} \mathrm{P}<0.05$ vs. model; ${ }^{\wedge} \mathrm{P}<0.05$ vs. MC; ${ }^{\circledR} \mathrm{P}<0.05$ vs. IC. MC, miR-27b mimics control; miR, microRNA; IC, miR-27b inhibitor control; d, days. Data are expressed as the mean \pm standard deviation of three experiments.

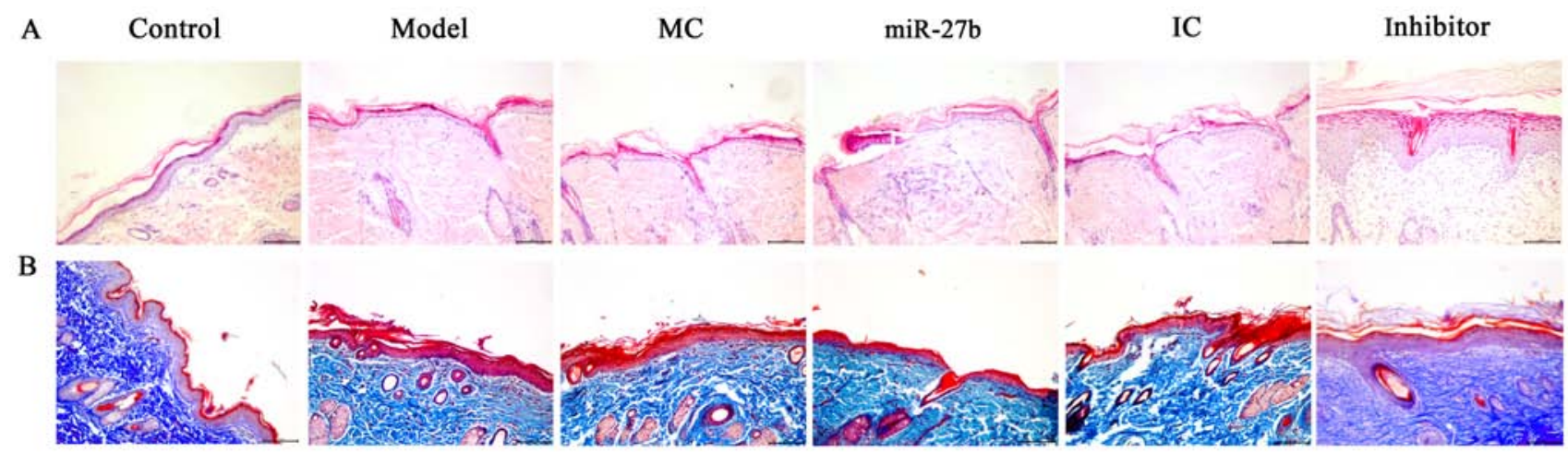

Figure 2. Observation of tissue morphology and collagen fibrosis in rats. (A) H\&E staining images (magnification, x400). (B) Masson staining images (magnification, x400). MC, miR-27b mimics control; miR, microRNA; IC, miR-27b inhibitor control.

the model, MC and IC groups exhibited disordered fibers and low levels of collagen synthesis. The number of fibroblasts observed to be stained with Masson bluing solution in the inhibitor group was markedly higher compared with the model group and the cells were arranged in an orderly manner. Furthermore, the number of fibroblasts in the miR-27b group was observably lower than that in the model group and the collagen fibers were bulky.

MMP-1, $\alpha-S M A$, collagen I and collagen III expression in rat skin tissue. MMP-1, $\alpha$-SMA, collagen I and collagen III expression in skin tissues was determined using RT-qPCR and western blot analysis. The mRNA and protein expression of these proteins in the model, MC and IC groups were significantly lower compared with the control group; however, there was no significant difference between those groups (Fig. 3A and B; $\mathrm{P}<0.05$ ). The expression of these proteins in the inhibitor group was significantly increased compared with the model group $(\mathrm{P}<0.05)$ and the reverse effect was observed in the miR-27b group compared with the model group $(\mathrm{P}<0.05)$. According to these results, miR-27b inhibition upregulated MMP-1, $\alpha$-SMA, collagen I and collagen III expression in vivo, thereby accelerating the healing of scald burn of the skin in rats.

Effects of miR-27b on the proliferation and migration of $B J$ cells. The RT-qPCR results demonstrated that there was no 
A

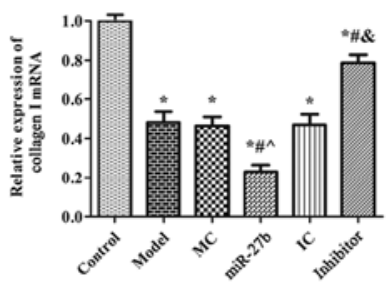

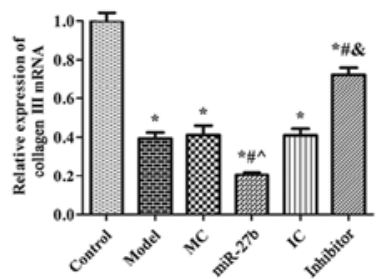
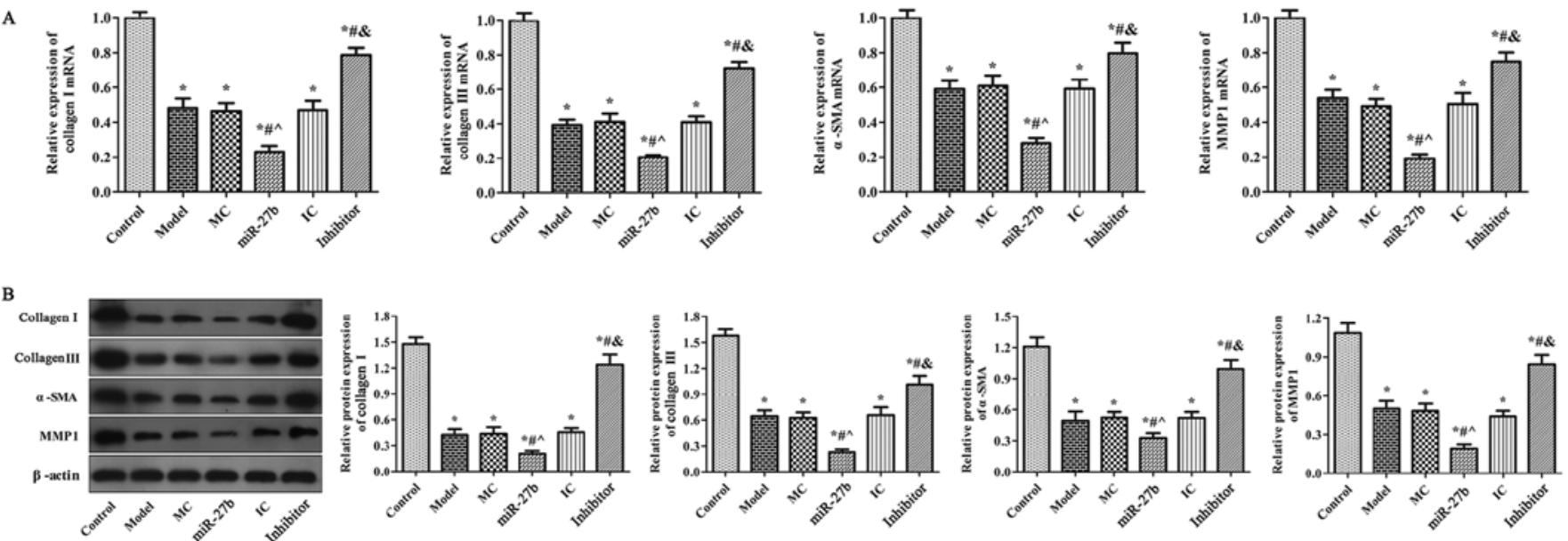

Figure 3. MMP1, $\alpha$-SMA, collagen I and collagen III expression in rat skin tissues was measured using (A) reverse transcription-quantitative PCR and (B) western blot analysis. ${ }^{\prime} \mathrm{P}<0.05$ vs. control group. ${ }^{\#} \mathrm{P}<0.05$ vs. model; ${ }^{\wedge} \mathrm{P}<0.05$ vs. MC; ${ }^{\circledR} \mathrm{P}<0.05$ vs. IC. MMP1, matrix metalloproteinase-1; $\alpha$ SMA, $\alpha$-smooth muscle actin; MC, miR-27b mimics control; miR, microRNA; IC, miR-27b inhibitor control. Data are expressed as the mean \pm standard deviation of three experiments.

A

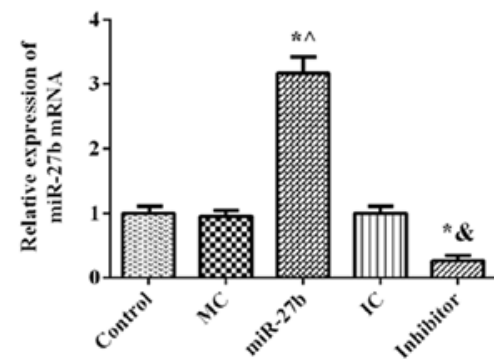

$\mathrm{C}$

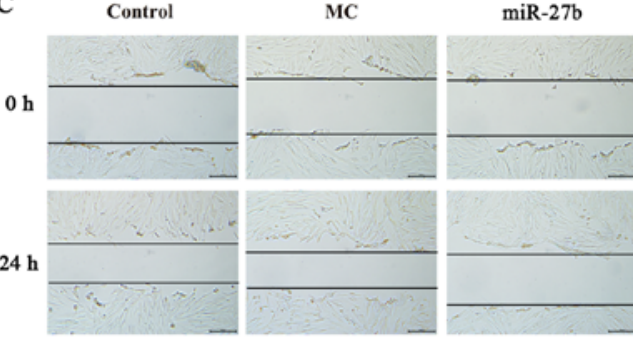

B

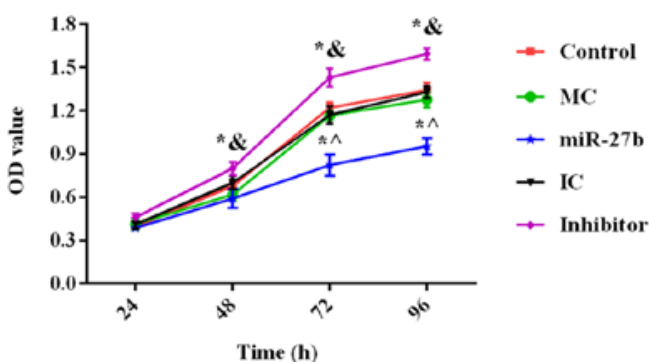

IC

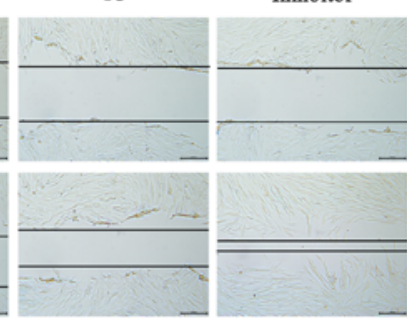

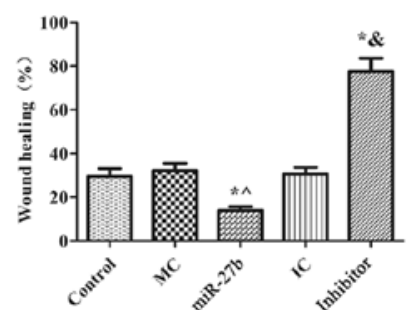

Figure 4. Effects of miR-27b on the proliferation and migration of BJ human fibroblast cells. (A) miR-27b expression in BJ cells was measured using reverse transcription-quantitative PCR. (B) BJ cell proliferation was measured via MTT assay. (C) BJ cell migration was measured using a wound-healing assay (magnification, $\mathrm{x} 200$ ). ${ }^{*} \mathrm{P}<0.05$ vs. control; ${ }^{\wedge} \mathrm{P}<0.05$ vs. $\mathrm{MC} ;{ }^{\&} \mathrm{P}<0.05$ vs. IC. miR, microRNA; MC, miR-27b mimics control; IC, miR-27b inhibitor control; $\mathrm{OD}$, optical density. Data are expressed as the mean \pm standard deviation of three experiments.

significant difference in miR-27b expression between the $\mathrm{MC}$, IC and control groups (Fig. 4A; $\mathrm{P}<0.05$ ). miR-27b expression in the miR-27b group was significantly increased compared with the $\mathrm{MC}$ and control groups $(\mathrm{P}<0.05)$. Furthermore, miR-27b expression in the inhibitor group was significantly decreased compared with the control and IC groups $(\mathrm{P}<0.05)$, indicating the successful transfection of miR-27b mimics and miR-27b inhibitors. Furthermore, there were no significant differences in $\mathrm{BJ}$ cell proliferation and migration in the $\mathrm{MC}$ and $\mathrm{IC}$ groups compared with the control group (Fig. 4B and C; $\mathrm{P}<0.05$ ). $\mathrm{BJ}$ cell proliferation and migration in the inhibitor group were significantly increased compared with those in the IC group $(\mathrm{P}<0.05)$, whereas the opposite effect was observed in the miR-27b group $(\mathrm{P}<0.05)$. These results indicated that miR-27b inhibition significantly increased $\mathrm{BJ}$ cell proliferation and migration.

Effect of miR-27b on MMP-1, $\alpha-S M A$, collagen I and collagen III expression in BJ cells. MMP-1, $\alpha$-SMA, collagen I and collagen III expression in BJ cells was determined using RT-qPCR and western blot analysis (Fig 5.). There was no significant difference between the MC, IC and control groups $(\mathrm{P}>0.05)$. Furthermore, mRNA and protein expression of these proteins in the inhibitor group were significantly increased compared with the control group $(\mathrm{P}<0.05)$ and the opposite effect was reported in the miR-27b group $(\mathrm{P}<0.05)$. These results demonstrated that miR-27b inhibition significantly upregulated MMP-1, $\alpha$-SMA, collagen I and collagen III 

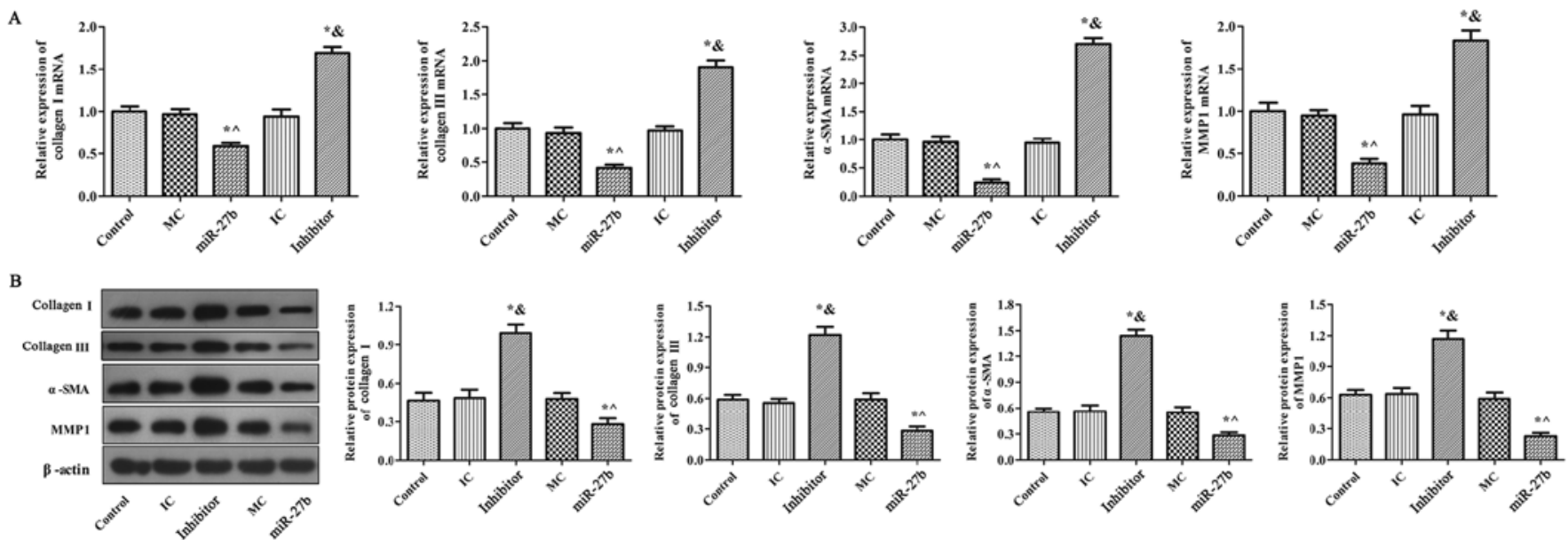

Figure 5. Effect of miR-27b on MMP1, $\alpha$-SMA, collagen I and collagen III expression in BJ cells. MMP1, $\alpha$-SMA, collagen I and collagen III expression in $\mathrm{BJ}$ cells was measured by (A) reverse transcription-quantitative $\mathrm{PCR}(\mathrm{B})$ western blot analysis. * $\mathrm{P}<0.05$ vs. control; ${ }^{\wedge} \mathrm{P}<0.05 \mathrm{vs}$. MC; ${ }^{\&} \mathrm{P}<0.05 \mathrm{vs}$. IC. miR, microRNA; MMP1, matrix metalloproteinase-1; $\alpha$-SMA, $\alpha$-smooth muscle actin; MC, miR-27b mimics control; IC, miR-27b inhibitor control. Data are expressed as the mean \pm standard deviation of three experiments.

expression in BJ cells. These results were consistent with the results obtained in rats.

\section{Discussion}

Scald burns are a common type of injury in clinical practice and wound management is an important part of scald treatment $(2,21)$. Infections are likely to occur during wound healing, which cause the wound to deepen (22). Therefore, the effectiveness of topical drug application to wounds directly affects the treatment course (23). The healing rate and time of scald burns may be used as direct, objective and effective evaluation indexes of wound healing and measuring the wound healing area may be used to further investigate the effect of drugs on wound healing (24).

In the present study, the effects of miR-27b on the healing rate of scalded skin were evaluated by establishing rat models of deep second-degree scald burns and injecting agents such as miR-27b mimics and miR-27b inhibitors into the wounds. The results demonstrated that miR-27b inhibition observably improved the healing rates of scald burns in rats, while miR-27b overexpression had the opposite effect. This indicated that miR-27b inhibition significantly accelerated the degree of scald healing in rats and may be an effective therapeutic target to promote scald repair.

Deep second-degree scald burns involve the deep dermis and a small amount of residual deep skin attachments (25). The fibroblasts proliferate to fill the wound and the epidermal stem cells proliferate and differentiate to form new epidermis and complete repair (26). In the present study, H\&E and Masson staining demonstrated that miR-27b inhibition on day 21 post-modelling significantly increased the number of fibroblasts and collagen in the wound surface and reduced the infiltration of inflammatory cell. Furthermore, in the wounds injected with miR-27b mimics, a large number of inflammatory cell infiltration, low amounts of new collagen and bulky collagen fiber morphology in scalded skin tissues were observed. The results also indicated that $\mathrm{miR}-27 \mathrm{~b}$ inhibition observably improved the morphology of scalded skin tissue and the degree of collagen fibrosis in rats.

Repaired skin tissue and cells require fibroblast proliferation for the healing of scald burns (27). Fibroblasts, the primary cells involved in wound healing, serve a vital role by multiplying, synthesizing and secreting collagen fibers and matrix components to improve wound healing (28). A previous study confirmed that increasing fibroblast proliferation and migration effectively promotes the healing speed of scald burns (29). Due to this, the present study hypothesized that inhibiting miR-27b expression may promote BJ cell proliferation and migration, thereby accelerating the healing of scald burns.

Scald wound healing involves angiogenesis, granulation tissue generation, extracellular matrix (ECM) protein synthesis, collagen storage and tissue remodeling (30). Collagen is an extracellular fibrin that promotes the formation of the intracellular matrix and repair of damaged cell structures (31). Type I and III collagen are the major components of collagen in the ECM and serve a major role in wound healing (32). The results of the present study demonstrated that miR-27b inhibition significantly upregulated the mRNA and protein expression of collagen I and III in scalded skin tissues of rats and in BJ cells, which may be associated with the accelerated healing of scalded skin in rats.

$\alpha$-SMA is a biomarker of activated fibroblasts and participates in the synthesis of type I and III collagen, and promotes fibrosis (33). A previous study reported that increased $\alpha$-SMA expression promotes the transformation of fibroblasts into myofibroblasts, accelerates wound contraction and shortens the healing time (27). Furthermore, MMPs are a group of proteases secreted by effector cells and are involved in ECM degradation (34). MMPs serve important roles in early wound clearance of necrotic tissue and are required for epithelial cell migration to infiltrate the wound surface (35). As the repair process progresses, MMPs are primarily located in the basal membrane expressed in fibroblasts in the late stages of tissue healing (36). MMP-1 is fibroblast-type collagenase, which promotes the clearance of necrotic tissue and serves an important role in ECM degradation (37). The results of the current 
study revealed that miR-27b inhibition significantly increased the mRNA and protein expression of $\alpha$-SMA and MMP-1 in scalded skin tissues of rats and in BJ cells. It has been previously reported that human adipose mesenchymal stem cells promote the differentiation and proliferation of fibroblasts by upregulating MMP-1, $\alpha$-SMA, collagen I and collagen III expression in skin wound tissues, thereby accelerating skin wound repair (38). Therefore, the current study suggested that inhibiting miR-27b expression may be a strategy to promote the healing of scalded skin in rats by upregulating the expression of MMP-1, $\alpha$-SMA, collagen I and collagen III.

In summary, the results of the present study demonstrated that miR-27b inhibition significantly promoted the growth, proliferation and collagen synthesis of cultured BJ cells in vitro. These results were consistent with the observational in vivo animal experiments, which revealed that miR-27b inhibition increased the wound healing rate and promoted wound collagen production. Therefore, in conclusion, the present study posits that promoting fibroblast proliferation and ECM synthesis is a possible method of inhibiting miR-27b expression in order to promote skin wound healing in rats.

\section{Acknowledgements}

Not applicable.

\section{Funding}

No funding was received.

\section{Availability of data and materials}

The datasets used and/or analyzed during the current study are available from the corresponding author on reasonable request.

\section{Authors' contributions}

JL conducted the experiments, data collection and interpretation. XW participated in study design, coordination of the experiments and data collection. QB participated in study design, data collection and data analysis and prepared the manuscript. FS participated in study design, data analysis, data interpretation and wrote the manuscript. All authors read and approved the final manuscript.

\section{Ethics approval and consent to participate}

The current study was approved by the Committee on Animal Protection and Use of the Affiliated Yantai Yuhuangding Hospital of Qingdao University (approval no. 2018-081303) and was conducted in strict accordance with the National Institute of Health guidelines (pub. no. 85-23; revised 1996).

\section{Patient consent for publication}

Not applicable.

\section{Competing interests}

The authors declare that they have no competing interests.

\section{References}

1. Kleina HT, Pádua T, Jacomino AP and May De Mio LL: Postharvest quality of plums in response to the occurrence of leaf scald disease. Postharvest Biol Technol 143: 102-111, 2018.

2. Andrews CJ, Kimble RM, Kempf M and Cuttle L: Evidence-based injury prediction data for the water temperature and duration of exposure for clinically relevant deep dermal scald injuries. Wound Repair Regen 25: 792-804, 2017.

3. Liu X, Zhao Y, Gao Y, Li D, Hu G, Zhu M, Yi K and Shao J: Modulations of the plasma scald on the downstream beam. Opt Commun 355: 290-295, 2015

4. Zhou J, Gao Z, Sun Y, Chen X, Wu X and Wang F: Effects of hypertonic sodium saline resuscitation on the liver damage of rats at early stage of severe scald. Zhonghua Shao Shang Za Zhi 33: 31-36, 2017 (In Chinese).

5. Ma M, Jiang T, Li N, Aliya A and Tuhan A: Treatment and mechanism of BMMSCs on deep II degree scald of hamster skin. Genet Mol Res 14: 8244-8251, 2015.

6. Xi P, Li Y, Ge X, Liu D and Miao M: Effect of nano-silver hydrogel coating film on deep partial thickness scald model of rabbit. Saudi J Biol Sci 25: 797-800, 2018.

7. Li D, Shang Y, Shen C, Li L, Zhao D, Ma L and Yu Y: Effects of Exendin-4 on pancreatic islets function in treating hyperglycemia post severe scald injury in rats. J Trauma Acute Care Surg 85: 1072-1080, 2018.

8. Liao X, Luo X, Dai L, Huang H and Guo X: Experimental study on adipose derived stem cells combined with chitosan chloride hydrogel for treating deep partial thickness scald in rats. Zhongguo Xiu Fu Chong Jian Wai Ke Za Zhi 33: 101-109, 2019 (In Chinese).

9. Shen C and Li D: 113 Effects of Exendin-4 on Pancreatic Islets Function in Treating Hyperglycemia Post Severe Scald Injury in Rats. J Burn Care Res 40 (Suppl. 1): S72-S73, 2019.

10. Thomou T, Mori MA, Dreyfuss JM, Konishi M, Sakaguchi M, Wolfrum C, Rao TN, Winnay JN, Garcia-Martin R, Grinspoon SK, et al: Adipose-derived circulating miRNAs regulate gene expression in other tissues. Nature 542: 450-455, 2017.

11. Vidigal JA and Ventura A: The biological functions of miRNAs: Lessons from in vivo studies. Trends Cell Biol 25: 137-147, 2015.

12. Michael JV, Wurtzel JGT, Mao GF, Rao AK, Kolpakov MA, Sabri A, Hoffman NE, Rajan S, Tomar D, Madesh M, et al: Platelet microparticles infiltrating solid tumors transfer miRNAs that suppress tumor growth. Blood 130: 567-580, 2017.

13. Colden M, Dar AA, Saini S, Dahiya PV, Shahryari V, Yamamura S, Tanaka Y, Stein G, Dahiya R and Majid S: MicroRNA-466 inhibits tumor growth and bone metastasis in prostate cancer by direct regulation of osteogenic transcription factor RUNX2. Cell Death Dis 8: e2572, 2017.

14. Liu L, Bi N, Wu L, Ding X, Men Y, Zhou W, Li L, Zhang W, Shi S, Song Y, et al: MicroRNA-29c functions as a tumor suppressor by targeting VEGFA in lung adenocarcinoma. Mol Cancer 16: 50, 2017.

15. Li D and Landén NX: MicroRNAs in skin wound healing. Eur J Dermatol 27S: S12-S14, 2017.

16. Soliman AM, Das S, Abd Ghafar N and Teoh SL: Role of MicroRNA in Proliferation Phase of Wound Healing. Front Genet 9: 38, 2018.

17. Veliceasa D, Biyashev D, Qin G, Misener S, Mackie AR, Kishore R and Volpert OV: Therapeutic manipulation of angiogenesis with miR-27b. Vasc Cell 7: 6, 2015.

18. Mu W, Hu C, Zhang H, Qu Z, Cen J, Qiu Z, Li C, Ren H, Li Y, He X, et al: miR-27b synergizes with anticancer drugs via p53 activation and CYP1B1 suppression. Cell Res 25: 477-495, 2015.

19. Bader A, Ebert S, Giri S, Kremer M, Liu S, Nerlich A, Günter CI, Smith DU and Machens HG: Skin regeneration with conical and hair follicle structure of deep second-degree scalding injuries via combined expression of the EPO receptor and beta common receptor by local subcutaneous injection of nanosized rhEPO. Int J Nanomedicine 7: 1227-1237, 2012.

20. Livak KJ and Schmittgen TD: Analysis of relative gene expression data using real-time quantitative PCR and the 2(-Delta Delta C(T)) Method. Methods 25: 402-408, 2001.

21. Sahu SA, Agrawal K and Patel PK: Scald burn, a preventable injury: Analysis of 4306 patients from a major tertiary care center. Burns 42: 1844-1849, 2016. 
22. Ramirez JI, Thomas DM, Neal DJ and Maguina P: A new injury prevention target: Summer hair braids. J Burn Care Res 39: 911-914, 2018.

23. Zhong L, Zhan JH, Luo JH and Cheng X: Effects of astragalus polysaccharide on cardiac dysfunction in rabbits with severe scald injury. Zhonghua Shao Shang Za Zhi 33: 668-676, 2017 (In Chinese)

24. Johnson BL III, Rice TC, Xia BT, Boone KI, Green EA, Gulbins E and Caldwell CC: Amitriptyline usage exacerbates the immune suppression following burn injury. Shock 46: 541-548, 2016.

25. Gao H, Liu Q, Zhang N, Wang H, Liu H and Sun H: Effect of Fenghua Scald Ointment on the Content of TNF- $\alpha$ and IL-10 in Rats with II-degree Deep Burn. Xiandai Shengwu Yixue Jinzhan 2015: 6, 2015.

26. de Campos EP, Trombini LN, Rodrigues R, Portella DL, Werner AC, Ferraz MC, de Oliveira RVM, Cogo JC, Oshima-Franco Y, Aranha N, et al: Healing activity of Casearia sylvestris Sw. in second-degree scald burns in rodents. BMC Res Notes 8: 269, 2015

27. Xu HL, Chen PP, ZhuGe D-L, Zhu Q-Y, Jin B-H, Shen B-X, Xiao J and Zhao Y-Z: ZhuGe DL, Zhu QY, Jin BH, Shen BX, Xiao J and Zhao YZ: Liposomes with Silk Fibroin Hydrogel Core to Stabilize bFGF and Promote the Wound Healing of Mice with Deep Second-Degree Scald. Adv Healthc Mater 6: 1700344, 2017.

28. Liu R, Wang S-M, Li Z-Y, Yu W, Zhang H-P and Zhou F-Q: Pyruvate in reduced osmolarity oral rehydration salt corrected lactic acidosis in sever scald rats. J Surg Res 226: 173-180, 2018.

29. Pelizzo G, Avanzini MA, Mantelli M, Croce S, Maltese A, Vestri E, De Silvestri A, Percivalle E and Calcaterra V: Granulation tissue-derived mesenchymal stromal cells: A potential application for burn wound healing in pediatric patients. J Stem Cells Regen Med 14: 53-58, 2018.

30. Zhang XG, Li XM, Zhou XX, Wang Y, Lai WY, Liu Y, Luo YC and Zhang JQ: The Wound Healing Effect of Callicarpa nudiflora in Scalded Rats. Evid Based Complement Alternat Med 2019: 1860680, 2019.

31. Zhan DC, Shen YS, Zhao YR and Meng FJ: Efficacy and safety of basic fibroblast growth factor in the treatment of burns: Protocol for a systematic review and meta-analysis of randomized controlled trials. Medicine (Baltimore) 98: e15102, 2019.
32. Baptista VIA, Quintana HT, Lazzarin MC, Benfato ID, De Carvalho FP, Le Sueur-Maluf L, De Oliveira CAM, Baptista JDS and De Oliveira F: Short time insulin treatment post burn improves elastic-collagen rearrangement and reepithelization. Connect Tissue Res 60: 230-239, 2019.

33. Yen $\mathrm{YH}, \mathrm{Pu} \mathrm{CM}$, Liu CW, Chen YC, Chen YC, Liang CJ, Hsieh JH, Huang HF and Chen YL: Curcumin accelerates cutaneous wound healing via multiple biological actions: The involvement of TNF- $\alpha$, MMP-9, $\alpha$-SMA, and collagen. Int Wound J 15: 605-617, 2018

34. Yang ML, Li YH, Tan Q, Li JT and Que LL: Effect of hydrocinnamoyl-L-valyl pyrrolidine on healing quality of deep partial-thickness scald wound in mice. Zhonghua Shao Shang Za Zhi 32: 658-666, 2016 (In Chinese).

35. Rocha J, Eduardo-Figueira M, Barateiro A, Fernandes A, Brites D, Pinto R, Freitas M, Fernandes E, Mota-Filipe H and Sepodes B: Erythropoietin reduces acute lung injury and multiple organ failure/dysfunction associated to a scald-burn inflammatory injury in the rat. Inflammation 38: 312-326, 2015.

36. Li XF, Zhang XJ, Zhang C, Wang LN, Li YR, Zhang Y, He TT, Zhu XY, Cui LL and Gao BL: Ulinastatin protects brain against cerebral ischemia/reperfusion injury through inhibiting MMP-9 and alleviating loss of ZO-1 and occludin proteins in mice. Exp Neurol 302: 68-74, 2018

37. Kim JY, Lee SH, Bae IH, Shin DW, Min D, Ham M, Kim KH, Lee TR, Kim HJ, Son ED, et al: Pyruvate Protects against Cellular Senescence through the Control of Mitochondrial and Lysosomal Function in Dermal Fibroblasts. J Invest Dermatol 138: 2522-2530, 2018.

38. Wang L, Hu L, Zhou X, Xiong Z, Zhang C, Shehada HMA, $\mathrm{Hu} \mathrm{B}$, Song $\mathrm{J}$ and Chen L: Exosomes secreted by human adipose mesenchymal stem cells promote scarless cutaneous repair by regulating extracellular matrix remodelling. Sci Rep 7: 13321, 2017.

This work is licensed under a Creative Commons Attribution-NonCommercial-NoDerivatives 4.0 International (CC BY-NC-ND 4.0) License. 